\title{
Energy demand and available technologies analysis for district heating cooling applications in a Science and Technology Park (PTA) in a Mediterranean country
}

\author{
R. Zubizarreta ${ }^{1 *}$, J.M. Cejudo $^{2}$, J.P. Jiménez ${ }^{3}$ \\ ${ }^{I}$ Andalusia Institute of Technology, Málaga, Spain \\ 2 Grupo de Energética, Escuela Técnica Superior de Ingenieros Industriales, UMA. Málaga, Spain \\ ${ }^{3}$ Andalusia Institute of Technology, Málaga, Spain \\ *Corresponding author.Tel: +349520287 10,Fax: +349520204 80,E-mail: rzubizarreta@iat.es
}

\begin{abstract}
The purpose of this paper is to present the results of the feasibility study for a district heating-cooling network to cover the energy demand in a Science and Technology Park under Mediterranean climate conditions. To evaluate the energy demand a bottom-up strategy has been followed: a building inventory has been carried out to define several building types according to use, envelope and glazing. Energy + has been used to obtain heating and cooling demand profiles for each building type and orientation. According to municipal development plans for PTA and forecast in business growth, the energy demand evaluation in a 10-years timeframe has been carried out.
\end{abstract}

Most appropriate technologies has been analyzed and evaluated: Cogeneration (gas turbine and alternative internal combustion engines), biomass boiler and conventional technologies have been evaluated with TRNSYS to obtain consumption profiles, consumption rates, efficiency indicators and energy losses. Finally an economic analysis has been done to technologies in a 20 years period to evaluate technology that better economic results address.

The main objective of this work is the promotion of the efficient and effective energy supply in areas with high energy consumption. DCH technology is widely used in the North of Europe and this paper try to demonstrate that this technology could be apply in Mediterranean areas successfully.

Keywords: District heating cooling: DHC; building energy analysis; energy demand; technical and feasibility study, district energy, thermal energy generation.

\section{Nomenclature (Optional)}

A effective area of supply........................... $\mathrm{m}^{2}$

EUI energy demand ........................... kWh

$R$ effective building type surface ratio ................................. $\mathrm{m}^{2} /$ building

ATE artificial thermal efficiency

$E_{e l}$ electric energy produced..... $k W h$

$E_{\text {input_by_fuel }}$ energy introduced in engine by fuel. $k W h$
$H$ heat amount provided to users $\mathrm{kWh}$

$\eta \quad$ efficiency level, ratio between useful output and input amount in plant components

$P_{\text {term }}$ thermal demand.

$E_{\text {el_cons }}$ electrical energy consumed by the facility. $k W h$

\section{Introduction}

Currently, as a result of improved quality of life for both, developed and developing countries, global energy demand grows at very high rates. For this reason, the responsible use of energy resources is crucial for a sustainable model to ensure power supply without compromising the natural resource depletion.

Energy system, as known today, is responsible for large energy losses. These losses result from the different transfer processes taking place from production to consumption points, resulting in an overall process inefficient. 
Within this framework, district heating and cooling, DHC in advance, is an alternative technology that improves power distribution processes as it is a local generation technology, and allow to incorporate different sources of energy supply (CHP, use of waste heat or solar thermal), thus constituting a technology that increases the efficiency of the complete cycle generation-consumption.

This paper presents the feasibility study of a DHC network to supply thermal energy to a group of companies located in Technology Park located in Málaga (Spain). It is remarkable the adaptation of this technology to Mediterranean climates in which winters are mild.

\section{Methodology}

\subsection{Demand characterization}

Energy demand evaluation is the starting and the most critical point to face a problem of this type, since it allows to determinate which are the heating and cooling needs in the consumption points to supply. The complexity in determining the demand for air conditioning in a group of buildings is not easy because the modelling a set of buildings is a complex tax. Several authors, such as Gustafsson [4], Heiple [5], Huang [6], Pedersen [7] or Segen [8] have developed various methods to solve this problem. In these papers, two types of strategies for estimating the demand could be found:

Top-down strategy: it is based on statistical methods for predicting the demand for a set of buildings based on aggregate data in large communities (cities or regions). Under this approach Pedersen [7] presents a method for calculating the demand for heat and electricity power planning adapted to large areas where heat demand is based on a regression analysis that uses the outdoor temperature as independent variable.

Bottom-up strategy: this case is the opposite that previous method, ie the starting point in this case is the estimated demand of different building types and total demand is calculated as the sum of the demands of each of the buildings that comprise. An inventory of buildings that are in the area of study is needed to use this method because each building is assigned to a "building type" that will carry the energy demand mean values. Mathematically:

$$
\text { Demand } \left.=\sum_{i=1}^{N}\left(A_{i} \cdot \sum_{j=1}^{M} E U I_{j} \cdot P_{i j}\right)\right)
$$

Where $\mathrm{A}$ is the net surface in each building, $\mathrm{EUI}_{\mathrm{j}}$ is annual energy demand for each building type ( $\mathrm{M}$ different types) and $\mathrm{P}_{\mathrm{ij}}$ is the matrix that set the relation between net building surface and building type.

Heiple [5], Huang [6] and Segen [8] have developed methods based on statistical data and numeric simulations with the aim of getting energy demand profiles for a set of buildings according to their location, envelope and use. In the same line, Chow [9] addresses the design of a distribution network by simulating energy demand for each building type using EnergyPlus [21] and analysing global system with TRNSYS software [22].

In this case, a bottom-up strategy has been chosen. Although it is unknown use and type of each actual building, it is known the surface of the extension $\left(651,334 \mathrm{~m}^{2}\right)$, the \% of the area for each use, the net area of each parcel and it is known that the type of construction is not very different from the buildings that are currently operating in the PTA (according to the municipal development plan). 
A deep study has been developed for the buildings currently in the PTA to get the main characteristics that define each building type and that will allow to define the thermal behaviour of the new buildings, the characteristics that have been identified are:

- Envelope characteristics.- due to the large variety used in PTA, the minimum values according to actual laws have been taking.

- Glass surface.- Up to three categories based on the \% of glass in the façade have been defined: low glazing ( $<10 \%)$, medium glazing (10-75\%) and high glazing $(>75 \%)$.

- Orientation of buildings.- defined by the final orientation of the building.

- Use.- considering the current business in PTA and the allocation for the several uses according to the partial plan, the following uses have been defined: hotel with shopping centres, babysitting, light industry and offices.

Several building types have been developed using Energy Plus based on these characteristics, this has allowed to obtain the hourly profiles for heating and cooling demand of each of them. In order to ensure the model convergences, the following conditions have been established:

- Load and temperature convergence tolerance value: 0,1.

- Heat balance algorithm: conduction transfer function [20].

The results obtained with the simulations have been validated and adjusted to reference values for the same purpose buildings that have been previously published by other authors [10], [11] and [12]. For instance table 1 show some reference values:

Table 1. Reference data consumption for buildings.

\begin{tabular}{cccc}
\hline Use & Mean Consumption $\left(\mathrm{kWh} / \mathrm{m}^{2}\right)$ & Cooling \% & Heating \% \\
\hline Offices & 131,57 & 42 & 4 \\
Hotel & 312,66 & 28 & 12 \\
\hline
\end{tabular}

Once the different models of buildings have been adjusted in terms of thermal behaviour, the possible location of different types of building have been allocated according to the uses defined in the partial plan and the main characteristics of actual buildings in the PTA. This division has allowed evaluating the total demand of all buildings according to equation 1 .

Another point considered in the analysis of the demand is the change in the occupation of parcels over time, this analysis will reveal the annual demand of thermal energy and thus affect the economic valuation of the proposed solutions. It has estimated by regression techniques based on the evolution experienced by PTA from its inception to the present. The result is shown in Figure 1:

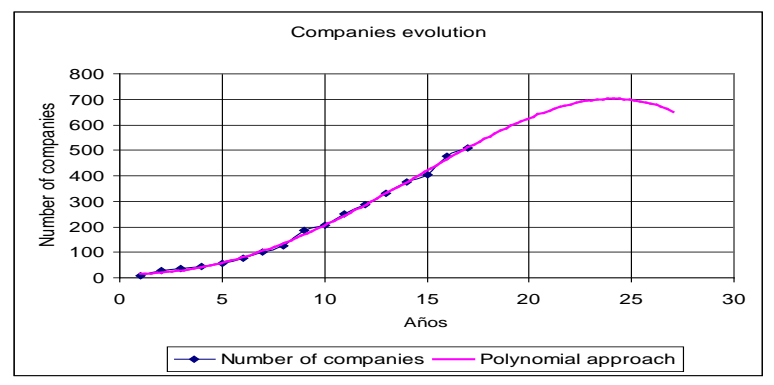

Fig 1. Number of companies installed in PTA

The regression curve of order 4 which adjusts the actual data with a regression coefficient of 0.9978 is: 


$$
y=-0,0031 \cdot x^{4}+0,0482 \cdot x^{3}+1,853 \cdot x^{2}-1,2072 \cdot x+14,605
$$

The energy demand values for each type of building together with the annual distribution of occupation of parcels allow to establish energy demand scenarios with a horizon of 10 years and make a more realistic assessment and economic valuation of the investments required.

Distribution system design has been calculated using peak demand values. DHC network is composed by a set of infrastructures that allow getting energy from producer to end-users. The design has been done considering the peak demand in year 10 because the infrastructure will not change during the entire period of operation thereof. The following components have sized: pipes, accumulation tank and pumping equipment.

\subsection{Generation technology alternatives}

After presenting the methodology for calculating demand, next question to ask is how the needed energy will be generated to cover the estimated demand. TRNSYS software will be used to study the different generation technologies; this will help to evaluate the efficiency and consumption parameters. The convergence of the models developed in TRNSYS to study the different technologies has been ensured by mean of energy balances. These balances guarantee good results from the models.

Previously, different technologies have been analyzed based on the work of Cardona [13], Marimon [14], Ortiga [15] and Söderman [16]; this analysis has permitted to reject those technologies that do not properly fit for the future expansion of the PTA and to work in-depth analysis of those technologies that fit better. Technologies that have been discussed are:

Biomass boiler.- the system includes a 20 MW biomass boiler for hot water production that feeds heating network, and the cooling-generating system. As support systems a 9 MW gas boiler and $6 \mathrm{MW}$ electric chillers is selected.

CHP.- cogeneration gas turbine and reciprocating internal combustion engine (ICE in advance) are the two types of systems that has been analysed, in both cases a 2 MW rated power equipment has been selected. Sizing has been performed considering the recommendations made by Cardona [13], Ortiga [15] and Söderman [16], using that system that maximizes the area under the aggregate demand curve. Besides Spanish legislative frame[18] should be ensured. The $2 \mathrm{MW}$ rated power guarantees both the system efficiency and the legislative requirements. In both cases, use waste heat from the engine or exhaust gases to generate useful heat will be used to heat water that will allow, in one hand, meet the demand for heating and hot water, and in the other hand, feed the cooling-generating system. As support systems a 9 MW gas boiler and 6 MW electric chillers is selected.

Waste treatment.- this technology has not been considered because there is no waste treatment plant close to the park that could serve as energy source to feed the DHC network.

Solar thermal energy.- it has not been considered as an alternative in order to supply the energy required. Both, the high costs associate with this technology and the high free spaces required mean that technology economically unfeasible (Bruno [17]).

Cooling generation technology.- double effect LiBr-water absorption chillers technology has been selected to cover cooling demand; this choice has been based on the analysis of advantages and disadvantages conducted by Marimon [14]. In all cases, a double effect 
absorption (BROAD 500) of 5.8 MW cooling capacity has been selected for cold water production. Additionally a water tank of $15,000 \mathrm{~m}^{3}$ has been selected.

Finally, this paper has been focused on biomass boiler and CHP technology, these three technologies have been evaluated and compared with using conventional technologies, in which the cooling demand is satisfied by chillers and demand heating is covered by a gas boiler.

The following ratios are considered to quantify the results of the different technologies modelled in this paper:

For CHP technologies the following ratio will be used: ATE artificial thermal efficiency defined as:

$$
A T E=\frac{E_{e l}}{E_{\text {input_by__fuel }}-\frac{H}{\eta_{\text {boiler }}}}
$$

Net primary energy consumption (NPEC).- it's defined to compare different technologies consumption rates. The mathematical expression for NPEC is:

$\mathrm{NPEC}=\left(E_{\text {el_cons }}-E_{\text {el }}\right) \cdot \mathrm{C}_{1}+\left(E_{\text {input_by_fuel }}\right) \cdot \mathrm{C}_{\mathrm{i}}$

where $C_{1}$ and $C_{i}$ are the conversion coefficients for final energy (electric, gas and biomass) to primary energy in Spain; its values are 2,67, 1,06 y 1,25 respectively [19].

$\mathrm{COP}_{\text {instlallation }}$ defined as:

$$
C O P_{\text {installation }}=\frac{P_{\text {term }}}{E_{e l_{-} \text {cons }}-E_{e l}}
$$

These ratios will allow, in one hand, ensuring that minimum standards required by Spanish Royal Decree 661/2007 [18] are met and, in the other hand, knowing the overall performance of the system. This will facilitate the subsequent economic evaluation.

\subsection{Economic analysis}

The economic analysis has been performed considering the following topics:

- Depreciation cost for investments.

- Maintenance cost.

- Operating cost (energy, human resources, overall costs).

- Revenues from energy sales.

These topics have permitted to evaluate investments in terms of return on investment (ROI in advance), payback period and cumulative cash flow. 


\section{Results}

Results obtained in the evaluation of demand, technology and economic assessment are as follows:

\section{Energy demand and DHC Network design parameters.}

Hourly profiles were obtained for heating and cooling demand in all buildings under study, considering the evolution of demand along the time as the occupation of the parcels is increasing. The monthly annual evolution for heating and cooling demand in the first 6 years is shown in Figure 2. It has been supposed that new buildings will be operative in the first six years. So, for years 7 to 10 , the demand does not suffer modifications.
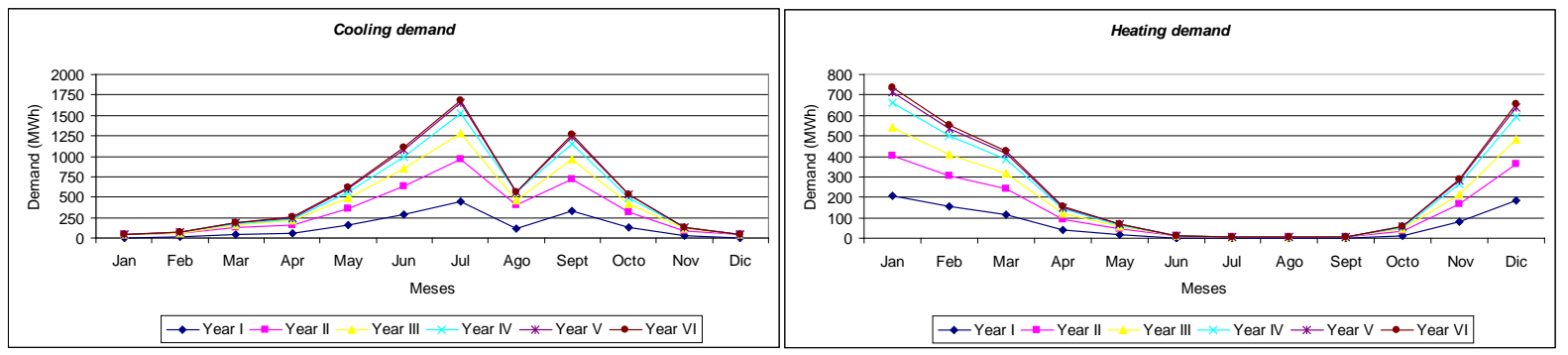

Fig 2. Cooling and heating demand evolution

As we can see, the cooling demand is highly reduced in August, since has been estimated the vacation period in this month.

In figure 3 the aggregate demand curve for heating and cooling in the year 10 is shown, this curve is very useful for sizing CHP equipment.
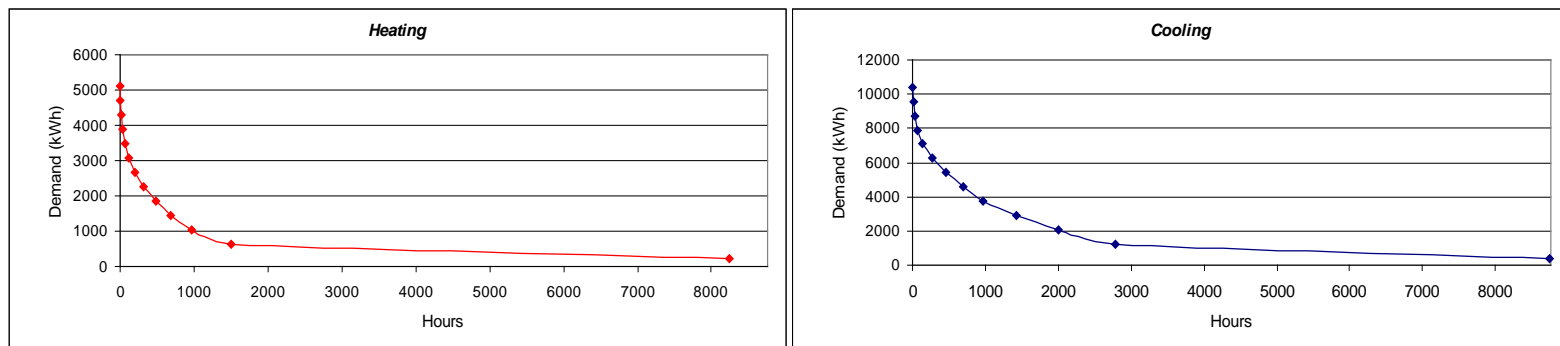

Fig 3. Aggregated demand curve for cooling and heating

As it is shown in the above figures, peak demand for year 10 has been set to $7.77 \mathrm{MW}$ for heating and 12.22 MW for cooling. With those maximum power values and considering a temperature drop for heating of $30{ }^{\circ} \mathrm{C}$ and $8{ }^{\circ} \mathrm{C}$ for cooling, the maximum network flow is obtained: $61.8 \mathrm{~kg} / \mathrm{s}$ for heating and $364.6 \mathrm{~kg} / \mathrm{s}$ for cooling. These values along with the requirements of pressure loss in the network, and energy loss have led to size the diameter and thickness of insulation for the main pipe network and pumping system. Table 2 shows the design values of each of the components:

Table 2. Design DHC network parameters.

\begin{tabular}{lcccc}
\hline & Pipes DN (mm) & $\begin{array}{c}\text { Isolate thickness } \\
(\mathrm{mm})\end{array}$ & $\begin{array}{c}\text { Power pumps } \\
(\mathrm{kW})\end{array}$ & $\begin{array}{c}\text { Tank volumen } \\
\left(\mathrm{m}^{3}\right)\end{array}$ \\
\hline Cooling & 600 & 7,1 & 315 & 15.000 \\
Heating & 350 & 5,6 & 75 & - \\
\hline
\end{tabular}




\section{Technologies evaluation}

Table 3 show the results for technologies performance ratios calculated using TRNSYS.

Table 3. Design DHC network parameters.

\begin{tabular}{cccc}
\hline & $\begin{array}{c}\text { Net primary energy } \\
\text { consumption (MWh) }\end{array}$ & COP installation & ATE \\
\hline Conventional tech & $27.030,55$ & 0,353 & - \\
Biomass boiler & $29.117,90$ & 0,328 & - \\
Gas ICE & $14.332,39$ & 0,666 & 0,566 \\
Gas Turbine & $22.533,64$ & 0,424 & 0,589 \\
\hline
\end{tabular}

\section{Economic analysis}

Table 4 show the economic analysis for each of the technologies evaluated and figure 4 show cumulative cash flow for each technology:

Table 4. Economic analysis.

\begin{tabular}{ccc}
\hline & ROI & $\begin{array}{c}\text { Payback } \\
\text { (years) }\end{array}$ \\
\hline Conventional tech & $<0 \%$ & 12,5 \\
Biomass boiler & $<0 \%$ & 16 \\
Gas ICE & $9,63 \%$ & 8 \\
Gas Turbine & $1,69 \%$ & 10 \\
\hline
\end{tabular}

\section{Conclusions}

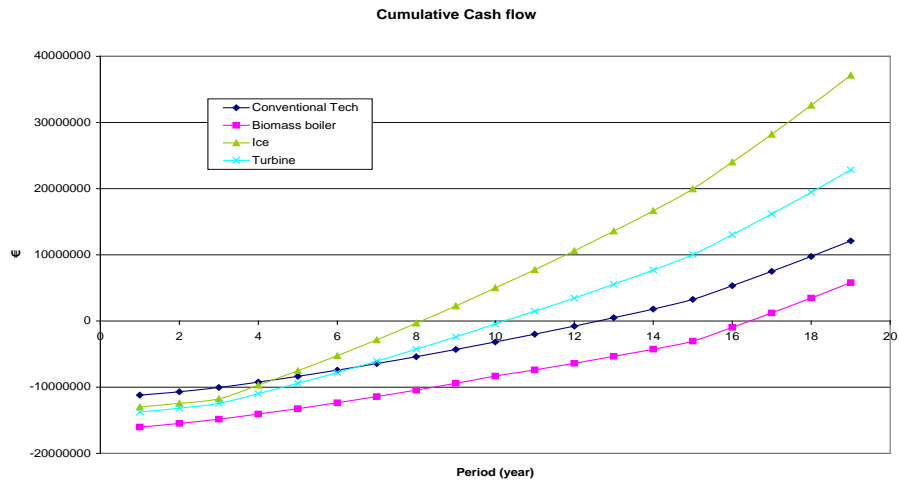

Figure 4. Cumulative cash flow analysis

As it could be seen in table 5 , the technology that offer the minimum pay back period is the Gas ICE following by the Gas Turbine, this fact is consequence of the electricity production associate with those technologies that offer economical benefits. For Gas ICE, the benefits begin to be positive since year 8 . It is obvious that infrastructure costs are very high in DHC. Economic figures are critical in the early years when buildings begin to establish in the technology park network and the energy demand is low.

The economic results showed support the implantation of a DHC network under the considerations done. The limitation for the feasibility resides in the future evolution of the new building openings. In this case the funding model of this type of technology must go through a public-private hybrid model in which the government support with soft credits to be repaid at the rate of new companies in the PTA are incorporating to DHC network, it will help owner company to obtain an acceptable incomes in the early years of operation.

\section{References}

[1] Directive 2009/28/EC of the European Parliament and of the Council of 23 April 2009 on the promotion of the use of energy from renewable sources.

[2] Directive 2002/91/EC of the European Parliament and of the Council of 16 December 2002 on the energy performance of buildings.

[3] Secretary of State for Energy, (2008). “The energy in Spain 2008”. Ministry of Industry, Tourism and Trade.

[4] S. Gustafsson. Optimal heating of large block of flats. Energy and buildings. 40 (2008) 1699-1708. 
[5] S. Heiple. Using building energy simulation and geospatial modelling techniques to determine high resolution building sector energy consumption profiles. Energy and buildings. 40 (2008) 1426-1436.

[6] Y.J. Huang, H. Akbari, L. Rainer, R. Ritschard. Prototypppical Commercial Buildings for 20 Urban Market Areas. Lawrence Berkeley Laboratory, Berkeley 1991. LBL-29798.

[7] L.Pedersen, J. Stang, R. Ulseth. Load prediction method for heat and electricity demand in buildings for the purpose of planning for mixed energy distribution systems. Energy and Buildings, 40 (2008) pp. 1124-1134

[8] O. Segen, E.M. Franconi, J.G. Koomey. Technology data characterizing space conditioning in commercial buildings: Applications to end-use forecasting with COMMEND 4.0 LBL-37065 1995.

[9] T.T. Chow, K.F. Fong, A.L.S. Chan, R. Yau, W.H. Au, V. Cheng. Energy modelling of district cooling system for new urban development. Energy and Buildings, 36 (2004) pp. 1153-1162

[10]Ministry of Economy. Saving Strategy and Energy Efficiency in Spain, 2004-2012: Building Sector. November 2003.

[11]Bohdanowicz, Paulina, Martinac, Ivo. "Determinants and benchmarking of resource consumption in Hotels - Case study of Hilton International and Scandic in Europe”. 2006.

[12] Pérez-Lombard, Luis, Adnot, Jérôme, Ortiz, José A.,Riviere, Philippe. "HVAC Systems energy comparison for an office building”. 2004.

[13]E. Cardona, A. Piacentino "A methodology for sizing a trigeneration plant in mediteranean areas" April 2003.

[14]M.A. Marimón. Diseño y caracterización de configuraciones avanzadas de sistemas de trigeneración en edificios. DEA 2008.

[15] J.Ortiga, J.C. Bruno, A. Coronas. Review of optimization models for the design of polygeneration systems in district heating and cooling networks. 17th European Symposium on Computer Aided Process Engineering - ESCAPE17. 2007.

[16] J. Söderman, F. Pettersson. Structural and operational optimisation of distributed energy systems. Applied Thermal Engineering, 2006, 26:1400-1408.

[17]J.C. Bruno, J. López, J. Ortiga, A. Coronas. Techno-economic design study of a large scale solar cooling plant integrated in a district heating and cooling network. 61st ATI National Congress - International Session "Solar Heating and Cooling”. Perugia, 2006.

[18] Royal Decree 661/2007 on the regulation of electricity in the special regime. BOE 126, p. 22846-86; 2007.

[19]Factores de conversión de consumo o producción a energía primaria (EP) y facot. IDAE. Instituto para la diversificación y ahorro de la energía. Ministerio de Industria, Turismo y Comercio; 2010.

[20] ASHRAE Handbook - Fundamentals. 2009.

[21] Energy Plus v5.0. Gard analytics. U.S. DOE Energy Efficiency and Renewable Energy (EERE)

[22] TRNSYS v16. TRaNsient SYstem Simulation Studio. Solar Energy Laboratory, Univ. of Wisconsin-Madison. 